\title{
The Reactants' Phase State: A Nonnegligible Factor in Tetralin Hydrogenation Catalysts Evaluation
}

\author{
Mingjian Luo, ${ }^{1,2}$ Qingfa Wang, ${ }^{1}$ Xiangwen Zhang, ${ }^{1}$ and Bing $\mathrm{Hu}^{2}$ \\ ${ }^{1}$ Key Laboratory for Green Chemical Technology of Ministry of Education, School of Chemical Engineering and Technology, \\ Tianjin University, Tianjin 300072, China \\ ${ }^{2}$ School of Chemistry and Chemical Engineering, Northeastern Petroleum University, Daqing 163318, China
}

Correspondence should be addressed to Mingjian Luo; luomingjian@nepu.edu.cn

Received 27 January 2014; Accepted 15 April 2014; Published 13 May 2014

Academic Editor: Deepak Kunzru

Copyright (c) 2014 Mingjian Luo et al. This is an open access article distributed under the Creative Commons Attribution License, which permits unrestricted use, distribution, and reproduction in any medium, provided the original work is properly cited.

\begin{abstract}
The effects of reactants' phase states (gas-liquid and single gas phase) on tetralin hydrogenation were investigated in the fixed bed. The kinetics of tetralin hydrogenation under different phase states was analyzed. Results showed that, without phase transition, the tetralin conversion increased with the rise of temperature. However, it decreased dramatically around the dew point of the feed at which the reactants' phase state transferred from gas-liquid phase into gas phase. It was also observed that the gas-liquid phase state was favorable to reduce the deactivation of catalyst in the tetralin hydrogenation.
\end{abstract}

\section{Introduction}

The deep hydrodearomatization of diesel fuels has been focused because of the environmental legislation and the clean-fuel production [1-3]. The development of catalytic technology for aromatic saturation and sulfur removal is highly desirable. Since the composition of diesel is complex, model compounds like toluene, tetralin, and naphthalene were commonly used in the evaluation of catalysts' performances. Without thermodynamic equilibrium limitation, the conversions of these model aromatics should increase with the rise of reaction temperature. However, some studies on the aromatic hydrogenation have found that the conversions of aromatics increased with the rise of temperature at a relatively low temperature but decreased with the further rise of temperature $[4,5]$; some others have showed an increasedecrease-increase tendency with the rise of temperature [610]; still others showed that hydrogenation depth was deeper at low temperature than at high temperature [5, 10-14]. Generally, these phenomena were ascribed to the exothermal character of the hydrogenation reaction. In other words, the thermodynamic equilibrium constrained the conversion of aromatics $[4,5,7-9,11]$. Nevertheless, the calculation results showed that the equilibrium conversion of naphthalene to tetralin could approach $100 \%$ under $5 \mathrm{MPa}$ and $300^{\circ} \mathrm{C}$; even at $350^{\circ} \mathrm{C}$ and $5 \mathrm{MPa}$, the equilibrium conversion was also higher than $95 \%$ (estimated from the figures in [3]). The hydrogenation of tetralin to decalin had a similar behavior. Furthermore, there were also studies with excellent aromatics conversion under similar reaction conditions [15]. Therefore, further study should be performed to investigate the reasons that caused the decrease of aromatics conversion with the rise of temperature, especially under relatively low reaction temperature.

Another probable reason that affects aromatics conversion is the reactants' phase state. The liquid phase vaporizes gradually with the rise of reaction temperature. At the dew point of the feed, all liquid phase vaporizes into vapor phase. When the reaction temperature is below the dew point of the feed, the liquid phase is existent, and the hydrogen would dissolve in the liquid phase and react with aromatics on the catalyst surface (gas-liquid-solid reaction mode). When the reaction temperature is above the dew point of the feed, all the liquid phase vaporizes into gas phase and reactants react on catalyst in gas-solid reaction mode. The two reaction modes are intrinsically different. This difference probably affects the 
hydrogenation activity of catalyst and leads to the decrease of aromatics conversion. Generally, model compounds are composed of aromatics and inert hydrocarbons; for example, naphthalene dissolves in $n$-hexadecane [16-19], $n$-tridecane $[20,21], n$-decane [22], $n$-heptane $[5,10-14,23]$, and benzene [4] or tetralin dissolves in $n$-dodecane [24], $n$-decane [22, $25,26], n$-heptane $[6-9,12,15,27,28], n$-hexane [29], and cyclohexane [30, 31]. The model compounds using light components as solvents are easier to vaporize and have lower dew point. The reaction mode of these model fuels might change from gas-liquid-solid to gas-solid mode. Accordingly, the conversion of aromatics might change during the phase transition.

In this work, tetralin was diluted in $n$-tetradecane, $n$ decane, and $n$-octane and then hydrogenated in a fixed bed under $5 \mathrm{MPa}, 220$ to $290^{\circ} \mathrm{C}$, and different $\mathrm{H}_{2} /$ oil ratios. The effects of reactants' phase states on tetralin conversion and products distribution were discussed.

\section{Experimental}

A mesoporous MCM-41 ( $\mathrm{Si} / \mathrm{Al}=24$, atom ratio) type catalyst containing $1.0 \mathrm{wt} . \%$ of $\mathrm{Pt}$ was prepared by incipient wetness impregnation of aqueous solution containing required amount of $\mathrm{Pt}\left(\mathrm{NH}_{3}\right)_{4} \mathrm{Cl}_{2}$. After Pt impregnation, the sample was kept at ambient temperature overnight and then dried at $110^{\circ} \mathrm{C}$ for $3 \mathrm{~h}$ and finally calcinated at $400^{\circ} \mathrm{C}$ for $4 \mathrm{~h}$.

The hydrogenation of tetralin was performed in a fixed bed reactor (inner diameter $12 \mathrm{~mm}$, length $600 \mathrm{~mm}$ ). $3 \mathrm{~g}$ catalyst (20 16 mesh) was placed in the isothermal zone of the fixed bed reactor. The reaction temperature was controlled by 4 thermocouples placed at the reactor wall and monitored with a thermocouple directly placed in the catalyst bed. Before the activity test, the catalyst was in situ reduced with $100 \mathrm{~mL} / \mathrm{min} \mathrm{H}_{2}$ at $400^{\circ} \mathrm{C}$ for $4 \mathrm{~h}$. The tetralin (20 wt.\%) dissolved in $n$-tetradecane, $n$-decane, or $n$-octane was supplied by a Series II piston pump with the flow rate of $0.3 \mathrm{~mL} / \mathrm{min}$. The $\mathrm{H}_{2}$ flow rate (generally $100 \mathrm{~mL} / \mathrm{min}, \mathrm{H}_{2} /$ oil $(\mathrm{v} / \mathrm{v})=333)$ was controlled by a mass flow controller. The reaction pressure $(5 \mathrm{MPa})$ was adjusted by a back pressure valve.

At each reaction condition, the product was collected after $3.5 \mathrm{~h}$ in order to achieve steady-state activity. The quantitative analysis of the reaction products was carried out using an Agilent 7890A GC system equipped with a capillary column (HP-PONA, $50 \mathrm{~m} \times 0.2 \mathrm{~mm} \times 0.5 \mu \mathrm{m}$ ) and FID detector. The products were preliminarily identified by an Agilent 6890 GC-MS system equipped with a capillary column (HP-5MS, $30 \mathrm{~m} \times 0.25 \mathrm{~mm} \times 0.25 \mu \mathrm{m})$. The hydrogenation products were $t$-decalin, $c$-decalin, $\mathrm{C}_{10}$ products (the ring opening products and the isomers of decalin), and cracking products $\left(\mathrm{C}_{3}\right.$ to $\mathrm{C}_{9}$ hydrocarbons; these compounds were ignorable at temperature below $270^{\circ} \mathrm{C}$ ). About $0.01 \% \sim 0.02 \%$ of $\mathrm{C}_{20}$ compounds, which were ascribed to the oligomerization of $\mathrm{C}_{10}$ component, were also detected at $290^{\circ} \mathrm{C}$. Although the amounts of $\mathrm{C}_{20}$ compounds were ignorable, they might affect the deactivation of catalyst.

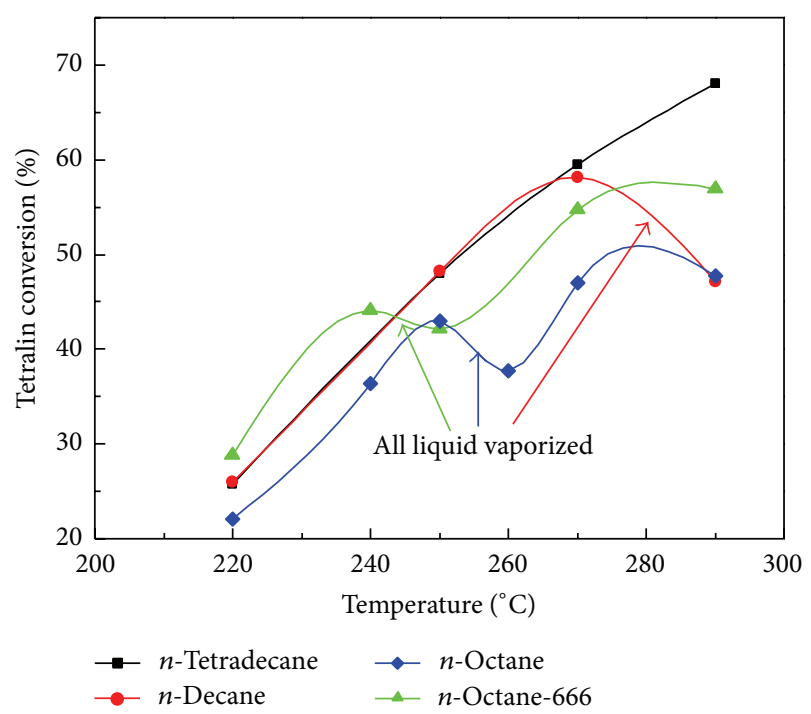

FIgURE 1: Tetralin conversion versus temperature in different solvents. Reaction conditions: $3 \mathrm{~g}$ catalyst, $5 \mathrm{MPa}, 0.3 \mathrm{~mL} / \mathrm{min}$ tetralin solvent, and $\mathrm{H}_{2} /$ oil $(\mathrm{v} / \mathrm{v})=333$ (666 in $n$-octane-666).

\section{Results}

Figure 1 showed the effects of different solvents on the tetralin conversion at the temperature range from $220^{\circ} \mathrm{C}$ to $290^{\circ} \mathrm{C}$. The tetralin conversion in $n$-tetradecane increased with the rise of temperature. However, there were transition points when $n$-decane and $n$-octane were used as solvents. When $n$ decane was used as solvent, the tetralin conversion decreased at $290^{\circ} \mathrm{C}$. When the solvent was alternated to $n$-octane, the tetralin conversion decreased at $260^{\circ} \mathrm{C}$ and then increased with the further temperature rise. Tetralin conversions in $n$ octane and $n$-decane are similar at $290^{\circ} \mathrm{C}$. But the values are much lower than in $n$-tetradecane. Increasing the $\mathrm{H}_{2} /$ oil ratio from 333 to 666 led to the increase of tetralin conversion and resulted in a lower temperature $\left(250^{\circ} \mathrm{C}\right)$ at which tetralin conversion began to decrease.

Figures 2 and 3 showed the influence of solvent on the $\mathrm{C}_{10}$ yield and the $t$-decalin/c-decalin ratio, respectively. Both the $\mathrm{C}_{10}$ yield and the $t$-decalin/c-decalin ratio increased with the rise of temperature in all the solvents. Differently from the results in $n$-tetradecane, two increased stages of $\mathrm{C}_{10}$ yield and $t$-decalin/c-decalin ratio were observed in $n$-octane. The temperature transition points of the two stages were similar to that of tetralin conversion in Figure 1. The transition of $\mathrm{C}_{10}$ yield and $t$-decalin/c-decalin ratio in $n$-decane can also be observed at $270^{\circ} \mathrm{C}$, but not as obviously as in $n$-octane.

Figure 4 showed the tetralin conversion in $n$-octane under different hydrogen flow rates at $250^{\circ} \mathrm{C}$. Firstly, the tetralin conversion increased with the increase of the $\mathrm{H}_{2}$ /oil ratio, and then it decreased dramatically between the $\mathrm{H}_{2}$ /oil ratios $=555$ and 666. Further increase in $\mathrm{H}_{2}$ /oil ratio led to the increase in tetralin conversion again. The retested values at $\mathrm{H}_{2}$ /oil ratios $=333$ and 666 were lower than the values in Figure 1, which indicate the deactivation of the catalyst. The yield of tetralin in naphthalene hydrogenation with the rise 


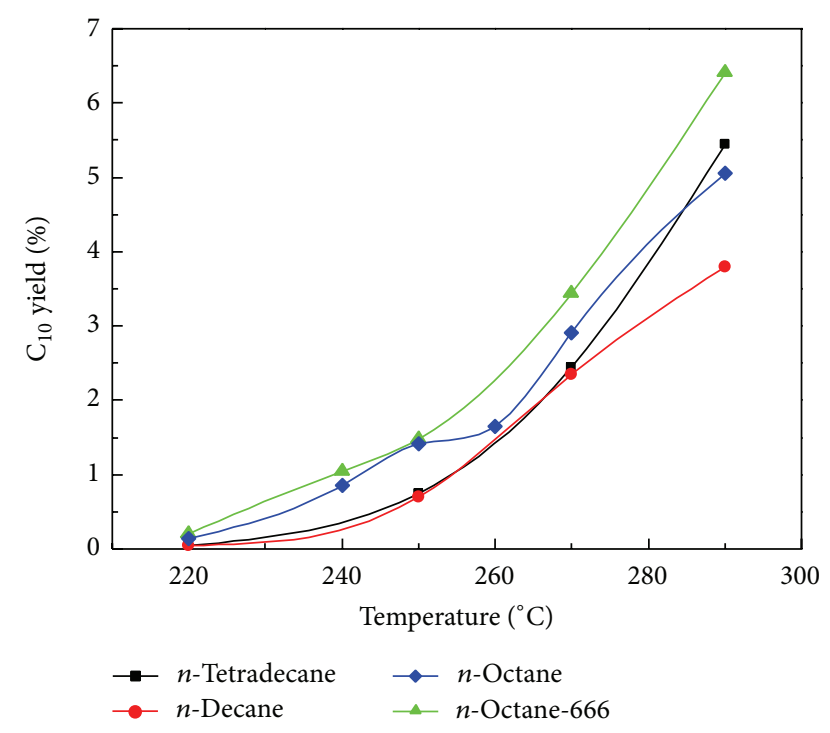

FIGURE 2: $\mathrm{C}_{10}$ yield versus temperature in different solvents.

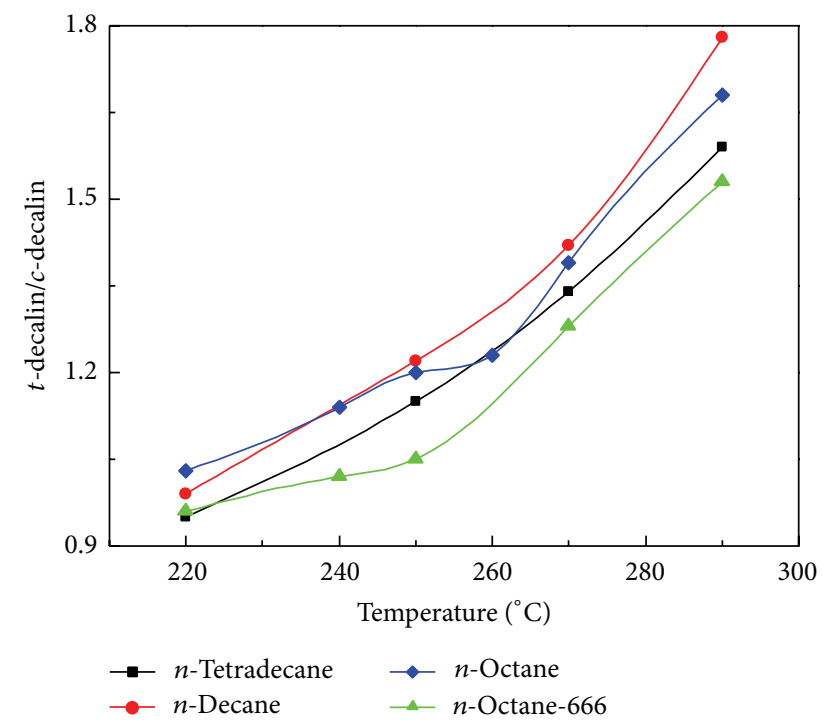

FIGURE 3: $t$-Decalin/c-decalin ratio versus temperature in different solvents.

of hydrogen/naphthalene ratio also exhibited the increasedecrease-increase tendency [28].

\section{Discussion}

\subsection{Effect of Phase State on the Catalytic Activity}

4.1.1. Relationship of Dew Point and Catalytic Activity. With the rise of temperature, the liquid phase vaporized gradually until all the liquid changed into gaseous phase at the dew point of the feed. The reaction modes below and above the dew point were intrinsically different, as illustrated in Scheme 1. Liquid phase exists at the temperature below the dew point of the feed. The hydrogen was dissolved in liquid

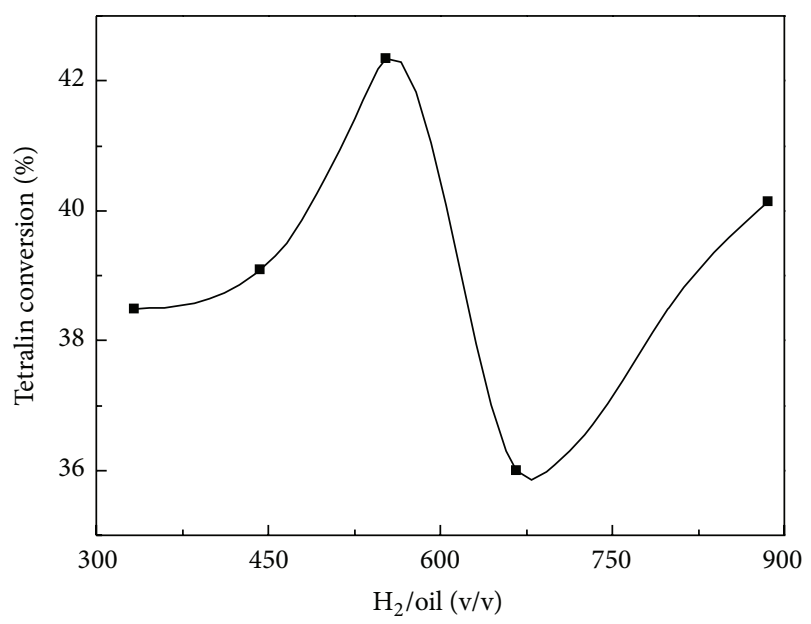

FIgURE 4: Tetralin conversion in $n$-octane under different $\mathrm{H}_{2} /$ oil ratio $\left(250^{\circ} \mathrm{C}\right)$.

TABLE 1: Dew points of feeds with different solvents.

\begin{tabular}{|c|c|c|c|c|}
\hline Solvent & $n$-Tetradecane $\mathrm{a}^{\mathrm{a}}$ & $n$-Decane ${ }^{\mathrm{a}}$ & $n$-Octane $\mathrm{e}^{\mathrm{a}}$ & $n$-Octane- $666^{\mathrm{b}}$ \\
\hline $\begin{array}{l}\text { Dew } \\
\text { point, } \\
{ }^{\circ} \mathrm{C}\end{array}$ & 356 & 297 & 266 & 239 \\
\hline
\end{tabular}

${ }^{a}$ Reaction conditions: 3 g catalyst, $5 \mathrm{MPa}, 0.3 \mathrm{~mL} / \mathrm{min}$ tetralin solvent, $\mathrm{H}_{2} / \mathrm{oil}$ $=333$, and ${ }^{\mathrm{b}} \mathrm{H}_{2} /$ oil $=666$.

phase and reacted with tetralin molecule on the catalyst surface. In other words, the reaction took place in the gasliquid-solid mode or the trickle bed mode. Tetralin and solvents are all vaporized into gas phase at the temperature above the dew point. Thus hydrogen and tetralin molecules diffused to the catalyst surface in gaseous phase, adsorbed on the active sites, and reacted with each other in the gassolid mode. The difference between these two reaction modes might affect the catalytic activity.

The dew points of reactants under the given conditions of pressures, liquid flow rates, and $\mathrm{H}_{2}$ /oil ratios can be calculated by equation of state. PR and SRK [32] equations of states are commonly used in phase equilibria modeling. They were compared in hydrogen-hydrocarbon phase equilibria calculation with experiment data. The SRK equation of state is a little more accurate than the PR equation of state. Thus the dew points were calculated using SRK equation of state (1) as follows and the results were listed in Table 1:

$$
\begin{gathered}
p=\frac{R T}{V-b}-\frac{a}{V(V+b)}, \\
a=a_{c} \cdot \alpha(T, \omega), \\
a_{c}=0.42748 \frac{R^{2} T_{c}^{2}}{p_{c}},
\end{gathered}
$$




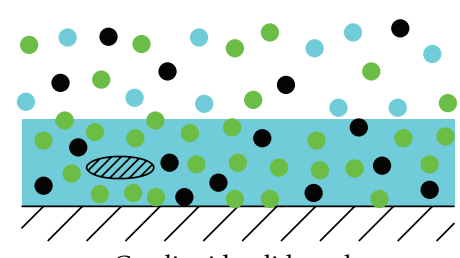

Gas-liquid-solid mode

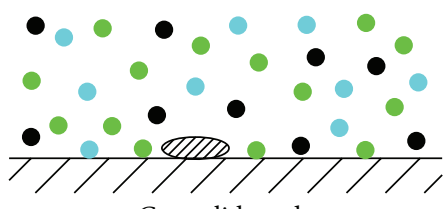

Gas-solid mode

- Aromatics Solvent

- Hydrogen Condensed molecule

Scheme 1: Illustration of gas-liquid-solid and gas-solid reaction modes.

$$
\begin{gathered}
b=0.08664 \frac{R T_{c}}{p_{c}}, \\
\alpha(T, \omega)=1+\left(0.48+1.574 \omega-0.176 \omega^{2}\right)\left(1-T_{r}^{0.5}\right) .
\end{gathered}
$$

The dew point of tetralin $/ n$-tetradecane system is $356^{\circ} \mathrm{C}$, which is much higher than the experimental temperatures. Liquid phase existed all through the experiment temperature range and only gas-liquid-solid reaction mode takes place. Thus the conversion of tetralin increased with the rise of temperature as shown in Figure 1. The dew point of tetralin $/ n$ decane system is $297^{\circ} \mathrm{C}$, which is close to the experimental temperature $290^{\circ} \mathrm{C}$. At this temperature the reaction takes place in gas-solid mode, and thus the tetralin conversion decreased. Similarly, the dew point of tetralin $/ n$-octane $\left(\mathrm{H}_{2} /\right.$ oil ratio $\left.=333\right)$ is $266^{\circ} \mathrm{C}$, and the conversion of tetralin decreased at $260^{\circ} \mathrm{C}$. Further rise in temperature can speed up the reaction and lead to the increase of tetralin conversion again. Increasing the $\mathrm{H}_{2}$ /oil ratio from 333 to 666 would bring down the dew point (from 266 to $239^{\circ} \mathrm{C}$ ). Therefore, the temperature at which tetralin conversion began to decrease also shifted to low (from 260 to $250^{\circ} \mathrm{C}$ ). In Figure 4, the tetralin conversion decreased between the $\mathrm{H}_{2} /$ oil ratio $=555$ and $\mathrm{H}_{2} /$ oil ratio $=666$. The calculated dew point of the feed at $\mathrm{H}_{2}$ /oil ratio $=555$ and pressure $5 \mathrm{MPa}$ was $246.6^{\circ} \mathrm{C}$, which was close to the experiment temperature $250^{\circ} \mathrm{C}$. These results indicated that there is substantial relationship between the reactants phase state and the catalytic activity.

4.1.2. Kinetic Analysis. The kinetic of tetralin hydrogenation was analyzed to investigate the effects of reactants' phase state on the catalytic activity. The Weisz-Prater parameter $C_{\mathrm{WP}}$ under the experimental conditions is estimated to be about 0.03 (with the method described in [33]); thus, the diffusion limitations can be neglected. The reverse reaction can also be neglected since the tetralin conversions are far from the equilibrium values [3]. With the existence of the liquid phase, the mass balance of tetralin can be expressed as

$$
-d\left(v_{L} C_{\mathrm{THN}, L}+v_{\mathrm{G}} C_{\mathrm{THN}, \mathrm{G}}\right)=k_{0} e^{-E_{a} / R T} C_{\mathrm{H}_{2}, \mathrm{~L}}^{n} C_{\mathrm{THN}, L}^{m} d V .
$$

Without the existence of the liquid phase, the mass balance of tetralin can be expressed as

$$
-d\left(v_{G} C_{\mathrm{THN}, G}\right)=k_{0} e^{-E_{a} / R T} C_{\mathrm{H}_{2}, \mathrm{G}}^{n} C_{\mathrm{THN}, \mathrm{G}}^{m} d V .
$$

Assuming vapor-liquid equilibrium is achieved at the inlet and every point of the catalyst bed, then the gas phase tetralin concentration $C_{\mathrm{THN}, G}=K C_{\mathrm{THN}, L}$ and $K=K_{0}=$ $C_{\mathrm{THN}, \mathrm{G}}^{0} / C_{\mathrm{THN}, L}^{0}$. The reaction order of the tetralin $m$ is chosen as 1 according to the previous reports $[3,24,34,35]$. The variations of $v_{L}, v_{G}, C_{\mathrm{H}_{2}, L}$, and $T$ are neglected to simplify the discussion, though they vary along the reactor due to the conversion of the reactant and the generation of heat during the reaction. Then the conversion of tetralin can be derived from integrating (2) and (3) with the boundaries $V=0$, $C_{\mathrm{THN}, L}=C_{\mathrm{THN}, L}^{0}\left(\right.$ or $\left.C_{\mathrm{THN}, G}=C_{\mathrm{THN}, \mathrm{G}}^{0}\right)$, and $V=V$, $C_{\mathrm{THN}, L}=C_{\mathrm{THN}, L}\left(\right.$ or $\left.C_{\mathrm{THN}, G}=C_{\mathrm{THN}, G}\right)$. For gas-liquid-solid mode,

$$
\begin{aligned}
- & \ln \left(\frac{C_{\mathrm{THN}, L}}{C_{\mathrm{THN}, L}^{0}}\right) \\
& =-\ln (1-x)=k_{0}^{\prime} e^{-E_{a} / R T} \frac{1}{v_{L}+\left(C_{\mathrm{THN}, \mathrm{G}}^{0} / C_{\mathrm{THN}, L}^{0}\right) v_{G}} C_{\mathrm{H}_{2}, L}^{n}
\end{aligned}
$$

and for gas-solid mode,

$$
-\ln \left(\frac{C_{\mathrm{THN}, G}}{C_{\mathrm{THN}, G}^{0}}\right)=-\ln (1-x)=k_{0}^{\prime} e^{-E_{a} / R T} \frac{1}{v_{\mathrm{G}}} C_{\mathrm{H}_{2}, G}^{n},
$$

with

$$
k_{0}^{\prime}=k_{0} V .
$$

Equations (4) and (5) imply that the tetralin conversion increases with the increase of the hydrogen concentration in liquid phase $C_{\mathrm{H}_{2}, L}$ (gas-liquid-solid reaction mode) or hydrogen concentration in gas phase $C_{\mathrm{H}_{2}, \mathrm{G}}$ (gas-solid reaction mode). The tetralin conversion also increases with the decrease of $v_{L}+\left(C_{\mathrm{THN}, \mathrm{G}}^{0} / C_{\mathrm{THN}, \mathrm{L}}^{0}\right) v_{\mathrm{G}}$ (gas-liquid-solid reaction mode, affected by volumetric flow rate of liquid and gas phase, and the tetralin concentration in liquid and gas phase) or $v_{G}$ (gas-solid reaction mode). The $v_{G}$ and $v_{L}+$ $\left(C_{\mathrm{THN}, \mathrm{G}}^{0} / C_{\mathrm{THN}, L}^{0}\right) v_{G}$ can be related to the practical residence time of tetralin. The greater the $v_{G}$ or $v_{L}+\left(C_{\mathrm{THN}, \mathrm{G}}^{0} / C_{\mathrm{THN}, L}^{0}\right) v_{\mathrm{G}}$, 
TABle 2: Parameters for (4) and (5).

\begin{tabular}{lcccc}
\hline$E_{a} \times 10^{4} \mathrm{~J} \mathrm{~mol}^{-1}$ & $n$ & \multicolumn{2}{c}{$k_{0}^{\prime}, \times 10^{5} \mathrm{~min} \mathrm{mmol}^{-1} \mathrm{~mL}^{-1} \mathrm{~mL}_{\text {cat }}^{-1}$} \\
$n$-Decane & $n$-Octane & $n$-Octane-666 \\
\hline 5 & 3 & 6.082 & 3.817 & 3.507 \\
\hline
\end{tabular}

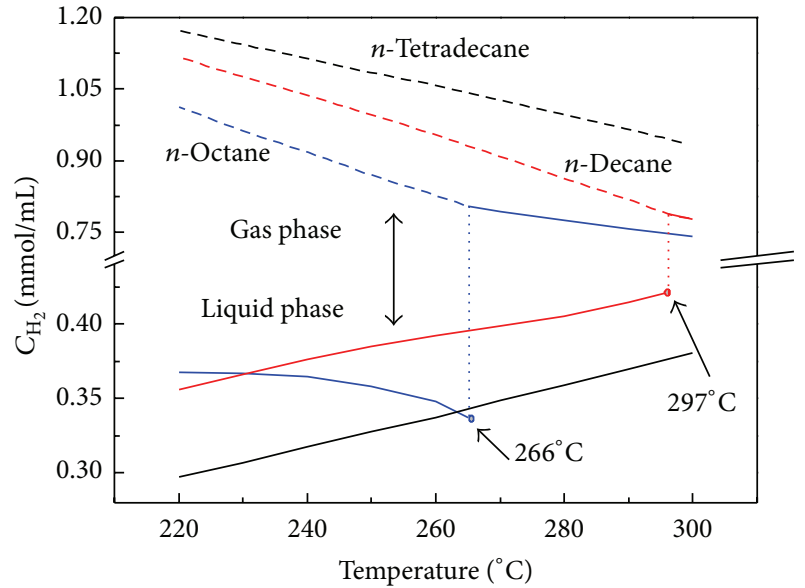

FIGURE 5: The hydrogen concentration in gas and liquid phases of different solvents calculated by SRK equation of state.

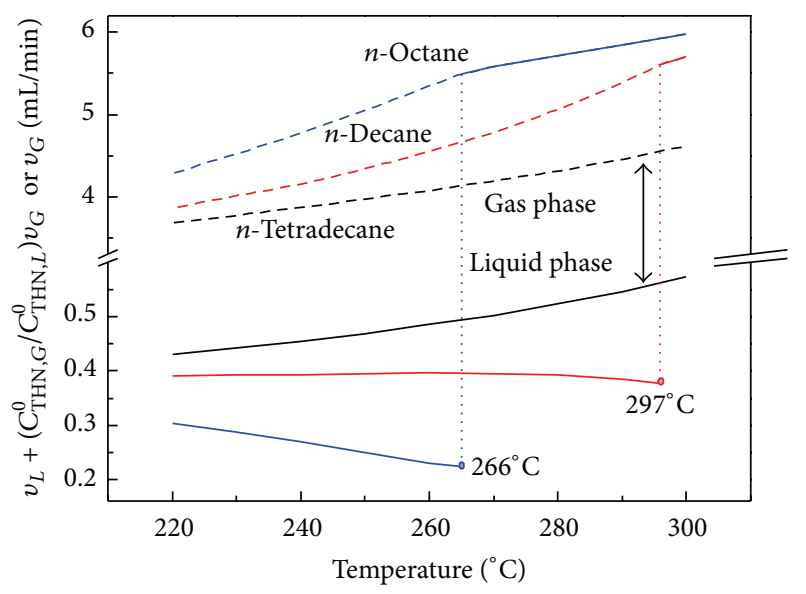

Figure 6: The $v_{L}+\left(C_{\mathrm{THN}, G}^{0} / C_{\mathrm{THN}, L}^{0}\right) v_{G}$ and $v_{G}$ of different solvents calculated by SRK equation of state.

the lower the practical residence time of tetralin. These values can also be calculated by SRK equation of state [32]. The results were illustrated in Figures 5 and 6 . Without phase transfer, the values of hydrogen concentration and $v_{L}+$ $\left(C_{\mathrm{THN}, \mathrm{G}}^{0} / C_{\mathrm{THN}, \mathrm{L}}^{0}\right) v_{\mathrm{G}}$ or $v_{\mathrm{G}}$ change smoothly. The gas phase hydrogen concentrations are about 2 3 times as large as the liquid phase ones, which benefits the tetralin conversion. However, the $v_{G}$ was about 8 25 times as large as the $v_{L}+$ $\left(C_{\mathrm{THN}, G}^{0} / C_{\mathrm{THN}, L}^{0}\right) v_{\mathrm{G}}$ and had a negative effect on the tetralin conversion. The combined effects of hydrogen concentration and $v_{G}\left(\right.$ or $\left.v_{L}+\left(C_{\mathrm{THN}, G}^{0} / C_{\mathrm{THN}, L}^{0}\right) v_{G}\right)$ lower down the tetralin conversion when all liquid is transferred into gas phase above the dew point.

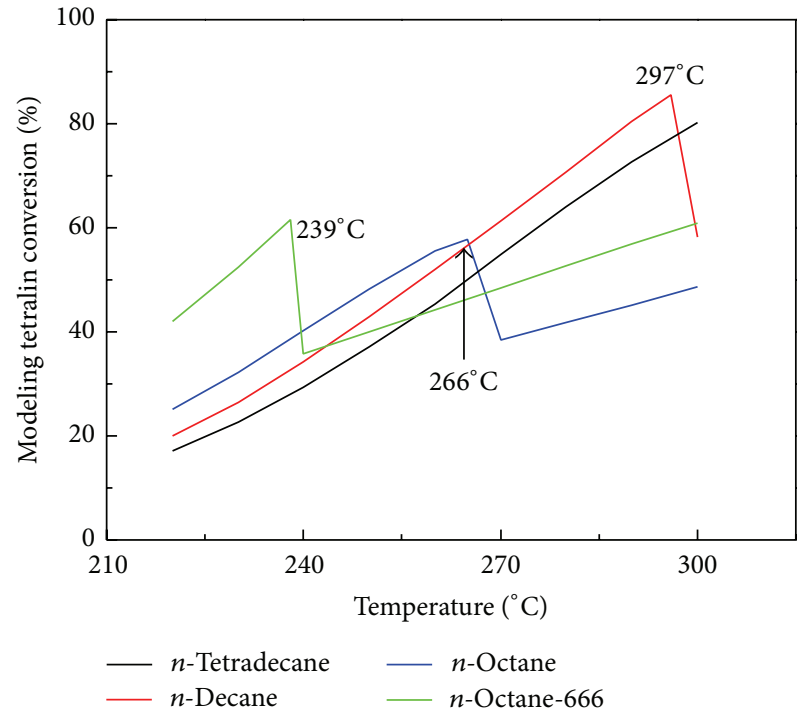

Figure 7: The tetralin conversion calculated by (4) and (5).

TABLE 3: Tetralin conversion after gas-liquid-solid or gas-solid reaction manner, \%.

\begin{tabular}{lccc}
\hline Temperature, ${ }^{\circ} \mathrm{C}$ & 250 & 290 & 250 (after 290) \\
\hline Tetralin $/ n$-octane & 44.51 & 49.87 & 41.61 \\
Tetralin $/ n$-tetradecane & 40.79 & 64.84 & 39.18 \\
\hline
\end{tabular}

The $E_{a}, n$, and $k_{0}^{\prime}$ of (4) and (5) were listed in Table 2. The activation energy $E_{a}$ was set to $50 \mathrm{~kJ} / \mathrm{mol}$, which was referred to as the values of most monocyclic aromatics $[3,36]$. The $k_{0}^{\prime}$ were regressed with experiment data for each reaction system. Without phase transition, the changes of hydrogen concentration can be neglected. Thus the reaction order $n$ with respect to hydrogen was set to zero in most of the studies $[24,35]$. The $n$ was set to 3 in this study because the hydrogen concentrations in liquid phase and gas phase were greatly different. Figure 7 showed the tetralin conversion calculated by (4) and (5). Similar tendencies can be observed in Figures 7 and 1 , though the calculation values could not exactly match with the experiment values. The errors might be caused by the error of phase equilibrium calculation. The same activation energies and reaction rate constants that were used for both gas-liquid-solid and gas-solid reaction modes might also cause the deviation.

4.2. Effect of Phase State on Catalyst Deactivation. The retest tetralin conversions (tetralin $/ n$-octane) at $\mathrm{H}_{2} /$ oil ratio $=333$ and $\mathrm{H}_{2}$ /oil ratio $=666$ in Figure 4 were lower than the values in Figure 1. These decreases might be caused by the deactivation of catalyst. Fresh catalyst was loaded to investigate 


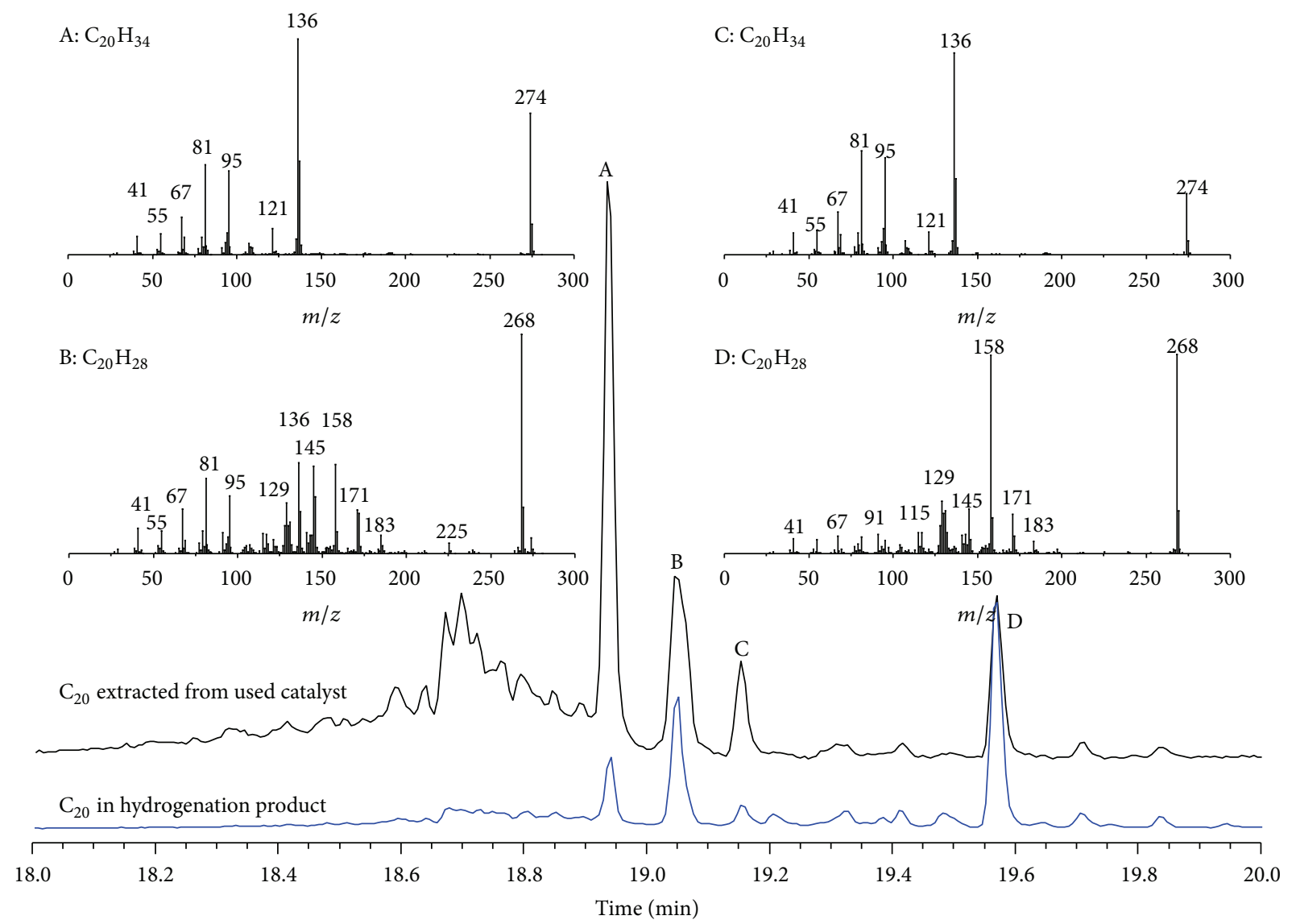

Figure 8: GC-MS spectra of $\mathrm{C}_{20}$ components in product and used catalyst.

the effect of gas-liquid-solid or gas-solid operating mode on catalyst deactivation. The results were listed in Table 3. The tetralin conversion at $250^{\circ} \mathrm{C}$ decreased from $44.51 \%$ to $41.61 \%$ after the gas-solid reaction at $290^{\circ} \mathrm{C}$ (tetralin $/ n$-octane), while it decreased from $40.79 \%$ to $39.18 \%$ after gas-liquid-solid reaction at $290^{\circ} \mathrm{C}$ (tetralin $/ n$-tetradecane). The deactivation of triphase mode was much slighter than the previous one.

The decalin dimers were detected in hydrogenation product at $290^{\circ} \mathrm{C}$ and in the used catalyst (extracted with $n$ tetradecane, and the obtained liquid was analyzed with GCMS). They might adsorb on the catalyst surface or active site and cause the deactivation $[37,38]$. Figure 8 showed the GC-MS spectra of the $\mathrm{C}_{20}$ components in the hydrogenation product and the used catalyst. The MS results showed that the $\mathrm{C}_{20}$ components were composed of multialicyclics and aromatic cycle. This indicated that more than two aromatic molecules condensed into a large molecule during the hydrogenation process. As illustrated in Scheme 1, the liquid solvent might dissolve these large molecules and carry them away. However, with the gas-solid mode, the large molecules were difficult to be desorbed and might occupy the active site. Thus the deactivation in the gas-solid reaction mode was much severer than in the gas-liquid solid one.

Similar to our experiment results, the available literatures which used light hydrocarbon (benzene [4], n-heptane [514], or cyclohexane [31]) as solvents are likely to show aromatics conversion transition with the increase of the reaction temperature. Generally, the ones that use heavy hydrocarbons like $n$-hexadecane, $n$-tridecane, and $n$-dodecane as solvents are likely to show that the conversion of aromatics increases with the rise of temperature. In addition, the light hydrocarbons were not the typical components of diesel fuel. We suggest that the model compounds for the evaluation of aromatic hydrogenation catalysts (especially the diesel fuel hydrodearomatization catalysts) should use suitable heavy hydrocarbons as solvents. Otherwise, the reactants' phase state should be taken into consideration during the catalyst evaluation.

\section{Conclusions}

The reactants' phase state had a significant effect on the catalytic activity of hydrogenation catalyst. The hydrogenation concentration that was available to the catalyst surface of gassolid reaction mode is $2 \sim 3$ times as high as that of gas-liquidsolid reaction mode, while the $v_{G}$ (gas-solid mode) is about $8 \sim 25$ times as large as the $v_{L}+\left(C_{\mathrm{THN}, G}^{0} / C_{\mathrm{THN}, L}^{0}\right) v_{G}$ (gas-liquidsolid mode). The combined effects of hydrogen concentration and $v_{G}\left(\right.$ or $\left.v_{L}+\left(C_{\mathrm{THN}, G}^{0} / C_{\mathrm{THN}, L}^{0}\right) v_{G}\right)$ cause tetralin conversion to dramatically decrease at the dew point of the feed. The gas-liquid-solid mode was preferred to reduce catalyst deactivation. Model compounds for aromatics hydrogenation catalysts evaluation should be absent in components that might bring in phase transfer under the test condition. 


\section{Notations}

C: Concentration, $\mathrm{mmol} \mathrm{mL}^{-1}$

$E_{a}$ : Activation energy, $\mathrm{J} \mathrm{moL}^{-1}$

$k_{0}$ : Reaction rate constant, $\min \mathrm{mmoL}^{-1} \mathrm{~mL}^{-1}$

$k_{0}^{\prime}$ : Reaction rate constant, $\min \mathrm{mmoL}^{-1} \mathrm{~mL}^{-1} \mathrm{~mL}_{\text {cat }}{ }^{-1}$

$R$ : Ideal gas constant, $8.314 \mathrm{~J} \mathrm{moL}^{-1} \mathrm{~K}^{-1}$

$T$ : Temperature, $\mathrm{K}$

$v$ : Volumetric flow rate, $\mathrm{mL} \mathrm{min}^{-1}$

$V$ : Catalyst bed volume, $\mathrm{mL}$.

Subscripts

0: $\quad$ Initial condition

G: $\quad$ Gas phase

$L: \quad$ Liquid phase

$m, n$ : Reaction order

$\mathrm{H}_{2}$ : Hydrogen

THN: Tetralin.

\section{Conflict of Interests}

The authors declare that there is no conflict of interests regarding the publication of this paper.

\section{Acknowledgment}

The financial supports by the National Natural Science Fund of China (Grant no. 90916022) were gratefully acknowledged.

\section{References}

[1] C. Song, "An overview of new approaches to deep desulfurization for ultra-clean gasoline, diesel fuel and jet fuel," Catalysis Today, vol. 86, no. 1-4, pp. 211-263, 2003.

[2] B. H. Cooper and B. B. L. Donnis, "Aromatic saturation of distillates: an overview," Applied Catalysis A: General, vol. 137, no. 2, pp. 203-223, 1996.

[3] A. Stanislaus and B. H. Cooper, "Aromatic hydrogenation catalysis: a review," Catalysis Reviews-Science and Engineering, vol. 36, no. 1, pp. 75-123, 1994.

[4] S. R. Kirumakki, B. G. Shpeizer, G. V. Sagar, K. V. R. Chary, and A. Clearfield, "Hydrogenation of Naphthalene over $\mathrm{NiO} / \mathrm{SiO}_{2}$ $\mathrm{Al}_{2} \mathrm{O}_{3}$ catalysts: structure-activity correlation," Journal of Catalysis, vol. 242, no. 2, pp. 319-331, 2006.

[5] S. Albertazzi, G. Busca, E. Finocchio, R. Glöckler, and A. Vaccari, "New Pd/Pt on Mg/Al basic mixed oxides for the hydrogenation and hydrogenolysis of naphthalene," Journal of Catalysis, vol. 223, no. 2, pp. 372-381, 2004.

[6] A. Infantes-Molina, J. Mérida-Robles, E. Rodríguez-Castellón, J. L. G. Fierro, and A. Jiménez-López, "Effect of molybdenum and tungsten on $\mathrm{Co} / \mathrm{MSU}$ as hydrogenation catalysts," Journal of Catalysis, vol. 240, no. 2, pp. 258-267, 2006.

[7] D. Eliche-Quesada, J. M. Mérida-Robles, E. RodríguezCastellón, and A. Jiménez-López, "Influence of the incorporation of palladium on Ru/MCM hydrotreating catalysts," Applied Catalysis B: Environmental, vol. 65, no. 1-2, pp. 118-126, 2006.
[8] A. Infantes-Molina, J. Mérida-Robles, E. Rodríguez-Castellón, B. Pawelec, J. L. G. Fierro, and A. Jiménez-López, "Catalysts based on Co/zirconium doped mesoporous silica MSU for the hydrogenation and hydrogenolysis/hydrocracking of tetralin," Applied Catalysis A: General, vol. 286, no. 2, pp. 239-248, 2005.

[9] D. Eliche-Quesada, J. M. Mérida-Robles, E. RodríguezCastellón, and A. Jiménez-López, "Ru, Os and Ru-Os supported on mesoporous silica doped with zirconium as mild thio-tolerant catalysts in the hydrogenation and hydrogenolysis/hydrocracking of tetralin," Applied Catalysis A: General, vol. 279, no. 1-2, pp. 209-221, 2005.

[10] S. Albertazzi, N. Donzel, M. Jacquin et al., "Role of the organic feed and the support acidity in hydrotreating reactions on PdPt on MCM-41 catalysts," Catalysis Letters, vol. 96, no. 3-4, pp. 157-164, 2004.

[11] S. Albonetti, G. Baldi, A. Barzanti et al., "Nanosized Pd/Pt and $\mathrm{Pd} / \mathrm{Rh}$ catalysts for naphthalene hydrogenation and hydrogenolysis/ring-opening," Catalysis Letters, vol. 108, no. 34, pp. 197-207, 2006.

[12] S. Albertazzi, M. Jacquin, D. J. Jones, M. Lenarda, L. Storaro, and A. Vaccari, "Activity of Rh-containing catalysts in naphthalene hydrogenation under pressure," Reaction Kinetics and Catalysis Letters, vol. 83, no. 1, pp. 11-17, 2004.

[13] S. Albertazzi, R. Ganzerla, C. Gobbi et al., "Hydrogenation of naphthalene on noble-metal-containing mesoporous MCM-41 aluminosilicates," Journal of Molecular Catalysis A: Chemical, vol. 200, no. 1-2, pp. 261-270, 2003.

[14] M. Mandreoli, A. Vaccari, E. Veggetti, M. Jacquin, D. J. Jones, and J. Roziere, "Vapour phase hydrogenation of naphthalene on a novel Ni-containing mesoporous aluminosilicate catalyst," Applied Catalysis A: General, vol. 231, no. 1-2, pp. 263-268, 2002.

[15] D. Eliche-Quesada, J. Mérida-Robles, P. Maireles-Torres et al., "Effects of preparation method and sulfur poisoning on the hydrogenation and ring opening of tetralin on NiW/zirconiumdoped mesoporous silica catalysts," Journal of Catalysis, vol. 220, no. 2, pp. 457-467, 2003.

[16] V. L. Barrio, P. L. Arias, J. F. Cambra, M. B. Güemez, B. Pawelec, and J. L. G. Fierro, "Hydrodesulfurization and hydrogenation of model compounds on silica-alumina supported bimetallic systems," Fuel, vol. 82, no. 5, pp. 501-509, 2003.

[17] V. L. Barrio, P. L. Arias, J. F. Cambra, M. B. Güemez, B. Pawelec, and J. L. G. Fierro, "Aromatics hydrogenation on silica-alumina supported palladium-nickel catalysts," Applied Catalysis A: General, vol. 242, no. 1, pp. 17-30, 2003.

[18] B. Pawelec, R. Mariscal, R. M. Navarro, S. Van Bokhorst, S. Rojas, and J. L. G. Fierro, "Hydrogenation of aromatics over supported Pt-Pd catalysts," Applied Catalysis A: General, vol. 225, no. 1-2, pp. 223-237, 2002.

[19] H. Yasuda, T. Sato, and Y. Yoshimura, "Influence of the acidity of USY zeolite on the sulfur tolerance of Pd-Pt catalysts for aromatic hydrogenation," Catalysis Today, vol. 50, no. 1, pp. 63$71,1999$.

[20] H. Liu, X. Meng, D. Zhao, and Y. Li, "The effect of sulfur compound on the hydrogenation of tetralin over a Pd-Pt/HDAY catalyst," Chemical Engineering Journal, vol. 140, no. 1-3, pp. 424-431, 2008.

[21] K. Ito, M.-A. Ohshima, H. Kurokawa, K. Sugiyama, and H. Miura, "Effect of residual Cl- derived from metal precursors on catalytic activity in the hydrogenation of naphthalene over supported Pd catalysts," Catalysis Communications, vol. 3, no. 11, pp. 527-531, 2002. 
[22] P. A. Rautanen, M. S. Lylykangas, J. R. Aittamaa, and A. O. I. Krause, "Liquid-phase hydrogenation of naphthalene and tetralin on $\mathrm{Ni} / \mathrm{Al}_{2} \mathrm{O}_{3}$ : kinetic modeling," Industrial and Engineering Chemistry Research, vol. 41, no. 24, pp. 5966-5975, 2002.

[23] S. J. Ardakani, X. Liu, and K. J. Smith, "Hydrogenation and ring opening of naphthalene on bulk and supported $\mathrm{Mo}_{2} \mathrm{C}$ catalysts," Applied Catalysis A: General, vol. 324, no. 1-2, pp. 9-19, 2007.

[24] R. C. Santana, S. Jongpatiwut, W. E. Alvarez, and D. E. Resasco, "Gas-phase kinetic studies of tetralin hydrogenation on PT/alumina," Industrial and Engineering Chemistry Research, vol. 44, no. 21, pp. 7928-7934, 2005.

[25] H. Li, B. Shen, X. Wang, and S. Shen, "Assembly of the presynthesized crystalline $\mathrm{AIPO}_{4}$ structure with alumina and its promotion for aromatic hydrogenation," Energy and Fuels, vol. 20, no. 1, pp. 21-25, 2006.

[26] P. A. Rautanen, J. R. Aittamaa, and A. O. I. Krause, "Liquid phase hydrogenation of tetralin on $\mathrm{Ni} / \mathrm{Al}_{2} \mathrm{O}_{3}$," Chemical Engineering Science, vol. 56, no. 4, pp. 1247-1254, 2001.

[27] H. Ma, X. Yang, G. Wen et al., "Coupled hydrogenation and ring opening of tetralin on potassium modified Pt/USY catalysts," Catalysis Letters, vol. 116, no. 3-4, pp. 149-154, 2007.

[28] M. Jacquin, D. J. Jones, J. Rozière et al., "Novel supported Rh, $\mathrm{Pt}$, Ir and Ru mesoporous aluminosilicates as catalysts for the hydrogenation of naphthalene," Applied Catalysis A: General, vol. 251, no. 1, pp. 131-141, 2003.

[29] S. G. A. Ferraz, F. M. Z. Zotin, L. R. R. Araujo, and J. L. Zotin, "Influence of support acidity of NiMoS catalysts in the activity for hydrogenation and hydrocracking of tetralin," Applied Catalysis A: General, vol. 384, no. 1-2, pp. 51-57, 2010.

[30] M. A. Arribas, P. Concepción, and A. Martínez, "The role of metal sites during the coupled hydrogenation and ring opening of tetralin on bifunctional Pt(Ir)/USY catalysts," Applied Catalysis A: General, vol. 267, no. 1-2, pp. 111-119, 2004.

[31] R. Contreras, J. Ramírez, R. Cuevas-García et al., "Preparation and characterization of Pt/HMFI-SBA-15 hybrid catalyst for tetralin transformation," Catalysis Today, vol. 148, no. 1-2, pp. 49-54, 2009.

[32] G. Soave, "Equilibrium constants from a modified RedlichKwong equation of state," Chemical Engineering Science, vol. 27, no. 6, pp. 1197-1203, 1972.

[33] H. S. Fogler, Elements of Chemical Reaction Engineering, Pearson Education, 4th edition, 2005.

[34] J. Chen, V. Mulgundmath, and N. Wang, "Accounting for vapor-liquid equilibrium in the modeling and simulation of a commercial hydrotreating reactor," Industrial and Engineering Chemistry Research, vol. 50, no. 3, pp. 1571-1579, 2011.

[35] S. Dokjampa, T. Rirksomboon, S. Osuwan, S. Jongpatiwut, and D. E. Resasco, "Comparative study of the hydrogenation of tetralin on supported $\mathrm{Ni}, \mathrm{Pt}$, and Pd catalysts," Catalysis Today, vol. 123, no. 1-4, pp. 218-223, 2007.

[36] J. W. Thybaut, M. Saeys, and G. B. Marin, "Hydrogenation kinetics of toluene on Pt/ZSM-22," Chemical Engineering Journal, vol. 90, no. 1-2, pp. 117-129, 2002.

[37] D. Kubička, N. Kumar, P. Mäki-Arvela et al., "Ring opening of decalin over zeolites: I. Activity and selectivity of proton-form zeolites," Journal of Catalysis, vol. 222, no. 1, pp. 65-79, 2004.

[38] M. Guisnet and P. Magnoux, "Coking and deactivation of zeolites. Influence of the pore structure," Applied Catalysis, vol. 54, no. 1, pp. 1-27, 1989. 

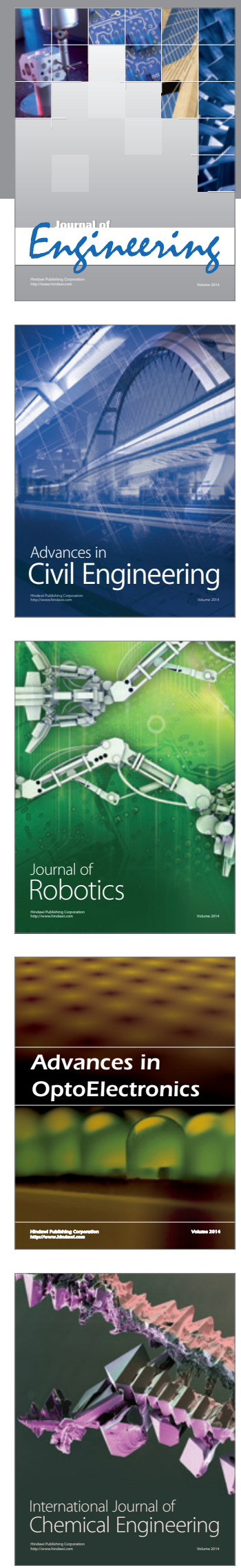

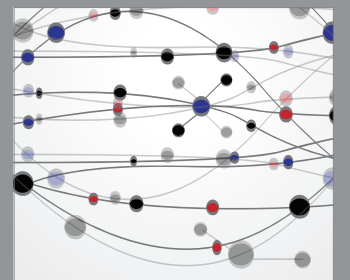

The Scientific World Journal
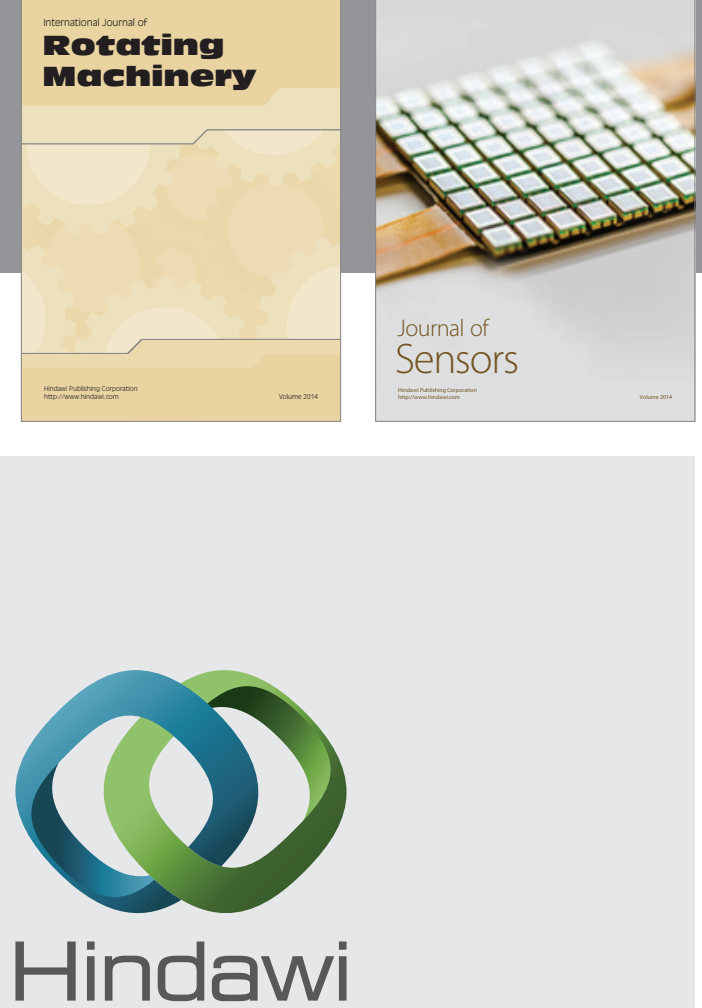

Submit your manuscripts at http://www.hindawi.com
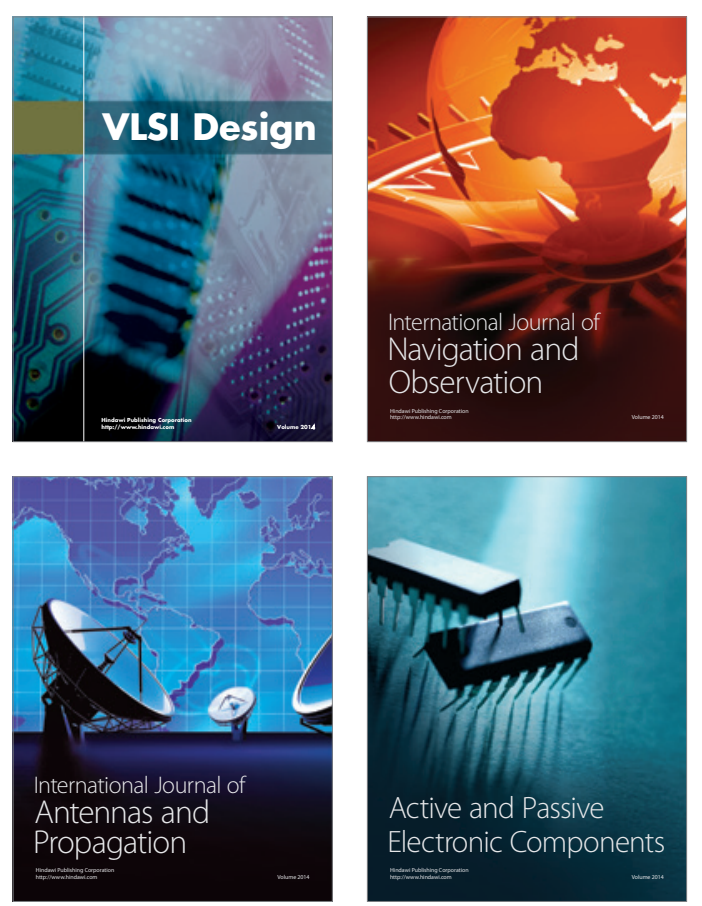
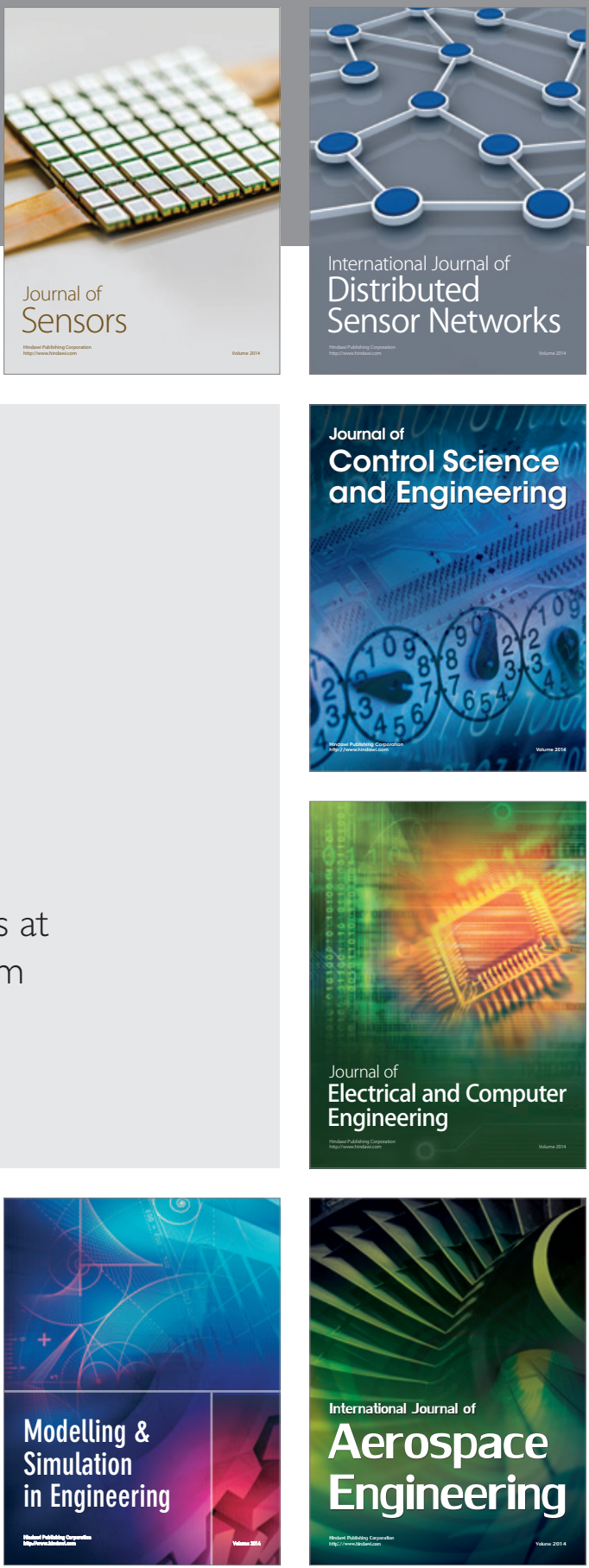

Journal of

Control Science

and Engineering
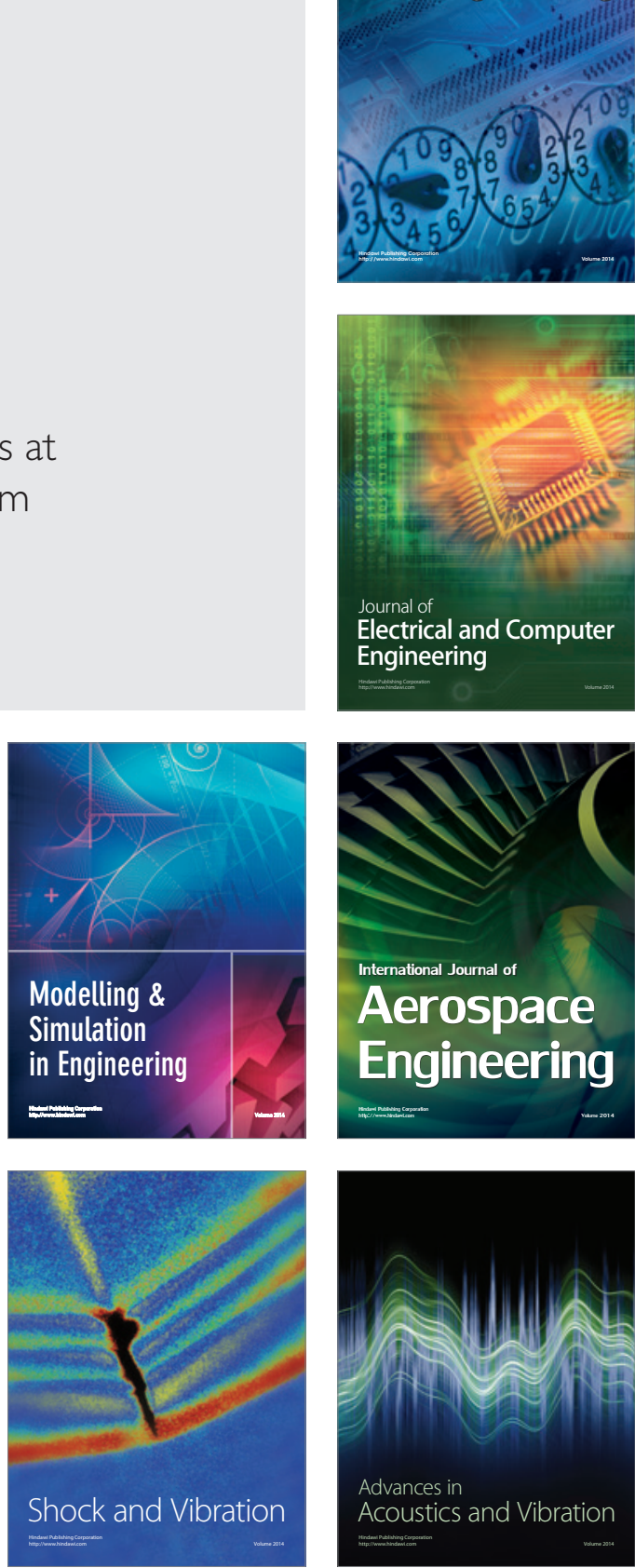